\title{
Desempenho de clones elite de batata para caracteres agronômicos e de qualidade industrial
}

\author{
Giovani Olegario da Silva*1, Arione da Silva Pereira², Nilceu Ricetti Xavier de Nazareno ${ }^{3}$, Rubens Ponijaleki ${ }^{4}$ \\ http://dx.doi.org/10.1590/0034-737X201562010009
}

\begin{abstract}
RESUMO
O objetivo deste trabalho foi verificar o desempenho de clones elite de batata, em relação a caracteres agronômicos e de qualidade industrial. Os experimentos foram realizados em Pelotas, RS, Canoinhas, SC, e Londrina, PR. Foi avaliado um conjunto de clones elite, pertencentes ao Programa de Melhoramento Genético de Batata, da Embrapa. O delineamento experimental foi o de blocos casualizados, com três repetições para Pelotas e Londrina e quatro para Canoinhas. Foram avaliados os caracteres massa total de tubérculos, massa comercial de tubérculos, número de tubérculos comerciais, percentagem de massa de tubérculos comerciais, massa média de tubérculos comerciais, peso específico, cor de fritura e ciclo vegetativo. A partir dos dados obtidos foram realizadas as análises de variância para cada local e teste de agrupamento de médias para cada caráter. Para identificação de clones apropriados ao mercado 'in natura', em que é fundamental o elevado potencial produtivo e precocidade, os clones mais promissores foram F80-03-06 e CL02-05, quando comparados à cultivar testemunha Ágata. Para o processamento industrial, em que o peso específico, a cor de fritura e o rendimento de tubérculo são caracteres importantes, destacou-se o clone F81-01-06, que apesar de não apresentar os maiores rendimentos totais, apresentou tubérculos grandes, ciclo vegetativo intermediário e boa aptidão para fritura, quando comparando-se ao cultivar testemunha Asterix.
\end{abstract}

Palavras-chave:Solanum tuberosum L., ciclo vegetativo, rendimento, peso específico, cor de palitos fritos.

\section{ABSTRACT}

\section{Performance of elite potato clones for agricultural and industrial quality traits}

The objective of this study was to evaluate the performance of elite potato clones for agricultural and processing quality traits. The experiments were carried out in Pelotas, State of Rio Grande do Sul, Canoinhas, State of Santa Cantarina, and Londrina, State of Paraná. A set of elite clones of the Embrapa Potato Breeding Program was evaluated. The experimental design was a randomized complete block, with three replications to Pelotas and Londrina, and four to Canoinhas. This experiment evaluated total mass of tubers, commercial mass of tubers, number of commercial tuber, mass percentage of commercial tuber, average mass of commercial tuber, specific gravity, frying color and vegetative cycle. Analysis of variance for each site and mean grouping test of each trait were performed from the data obtained in the experiment. By examining the results from the perspective of identifying the most suitable clones for fresh market, where high yield potential and early maturity are essential, compared to the control cultivar Ágata, the clones that appeared as the most promising were F80-03-06 and CL02-05. For processing, for which the specific weight, frying color, tuber yield are important traits clone F81-01-06 stood out, despite not having the highest yields, it has large tubers, intermediate vegetative cycle and good suitability for frying, in comparison to . the control cultivar Asterix.

Key words: French fry color, specific gravity, Solanum tuberosum L., vegetative cycle, yield.

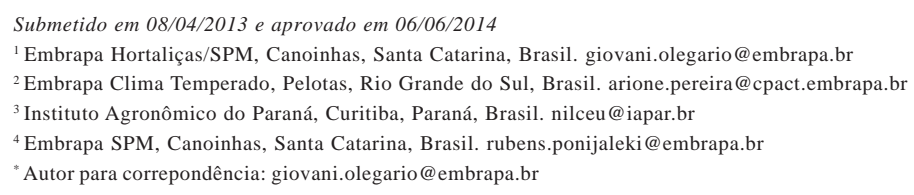




\section{INTRODUÇÃO}

Na maior parte, os cultivares de batatas utilizados atualmente no Brasil foram desenvolvidos na Europa. A produtividade desses cultivares, sob as condições brasileiras de clima e solo, é inferior à verificada nos países de origem (Silva et al., 2012), por terem sido selecionados sob condições de fotoperíodo longo e de baixa pressão de alguns fatores bióticos que afetam a cultura no Brasil. Esses cultivares, quando plantados em condições subtropicais e tropicais do país, apresentam um ciclo vegetativo mais curto (Rodrigues, 2006) e, por conseguinte, têm menor produção de fotossintetizados, em relação ao que ocorre nos países temperados. Para conseguir maior rendimento, é necessária a utilização de grande quantidade de insumos, onerando a produção e causando impacto negativo ao ambiente e, consequentemente, à sustentabilidade da cultura. Desta forma, a obtenção de cultivares nacionais, adaptados às condições de cultivo das diversas regiões produtoras brasileiras, com resistência às principais doenças, é a alternativa mais viável para tornar a cultura mais produtiva e rentável para o agricultor (Gadum et al., 2003).

Em regiões de clima temperado, os cultivares com ciclo vegetativo mais longo (>130 dias) são mais produtivos do que aqueles mais precoces. Comportamento semelhante verifica-se nas condições tropicais. Por essa razão, tem sido sugerida a seleção de clones tardios como estratégia para aumentar a produtividade da cultura em condições tropicais (Silva \& Pinto, 2005; Rodrigues et al., 2009). No entanto, os produtores brasileiros preferem cultivares precoces (Dias et al., 2003; Rodrigues et al., 2009), porque possibilitam a realização de maior número de cultivos por ano, menor tempo de exposição das plantas a intempéries, menor risco de doenças e pragas e menor demanda de irrigação. Além disso, os cultivares precoces permitem colher antecipadamente a cultura, dependendo de cotação do produto no mercado. Assim, o ciclo vegetativo é um caráter importante para os programas de melhoramento de batata.

A demanda por produtos industrializados da batata é crescente no Brasil, por causa das mudanças nos hábitos alimentares e da necessidade de se obter comida semipronta e produtos mais uniformes e práticos (Freitas et al, 2006). Há também aumento do número de cadeias de restaurantes, que demanda matéria-prima de alta qualidade para processamento industrial. Há requerimentos específicos quanto à qualidade dos tubérculos de batata para processamento industrial, como alto peso específico e baixo teor de açúcares redutores, além de ausência de distúrbios fisiológicos (Souza et al., 2011). O peso específico é um caráter importante, por ser relacionado com o teor de massa seca nos tubérculos. Peso específico mais elevado proporciona ao produto final maior rendimento na industrialização, menor absorção de gordura durante a fritura, além de influenciar na textura e no sabor (Silva et al., 2012). O baixo teor de açúcares redutores evita o escurecimento dos produtos processados, que compromete a aparência, a textura e o sabor do produto frito.

Diante do exposto, o objetivo deste trabalho foi verificar o desempenho de clones elite de batata, em relação a caracteres agronômicos e de qualidade industrial.

\section{MATERIAIS E MÉTODOS}

Os experimentos foram realizados nos campos experimentais da Embrapa Clima Temperado, em Pelotas, RS ( $31^{\circ} \mathrm{S}, 52^{\circ} \mathrm{O}, 50 \mathrm{~m}$ a.n.m.), do Escritório da Embrapa Produtos e Mercado, em Canoinhas, SC $\left(26^{\circ} \mathrm{S}, 50 \mathrm{~W}\right.$, 839 m a.n.m.), e do Instituto Agronômico do Paraná, em Londrina, PR (23 $\mathrm{S}, 51^{\circ} \mathrm{W}, 585 \mathrm{~m}$ a.n.m.). O solo da região de Canoinhas classifica-se como Cambissolo Háplico e o clima, segundo Köppen, é Mesotérmico Úmido. Em Pelotas, o plantio foi realizado em solo do tipo Podzólico Vermelho-Amarelo e o clima da região é classificado, segundo Köppen, como Temperado. Em Londrina, o solo utilizado é classificado como Latossolo Vermelho eutroférrico e o clima é Subtropical Úmido Mesotérmico (Embrapa, 2006). As condições climáticas não apresentaram anormalidade para os locais e épocas de cultivo.

Em cada local, foi avaliado um conjunto de clones elite, pertencente ao Programa de Melhoramento Genético de Batata, da Embrapa, sendo que os clones F53-01-06, F85-01-06, F74-26-06, F52-03-06, F81-01-06, F63-01-06, F119-01-06, F52-02-06, F74-23-06, F79-01-06, F68-04-06, F80-03-06 e as testemunhas Ágata (para mercado 'in natura') e Asterix (para processamento industrial) foram avaliados nos três locais; os clones F48-07-06 e F27-0306, em Canoinhas e Londrina e os clones CL02-05 e F8801-05, apenas em Canoinhas. Em Londrina, o plantio foi realizado no dia 03 de maio de 2010, em Pelotas, no dia 16 de março de 2011 e, em Canoinhas, em 17 de agosto de 2011. A colheita foi efetuada 110 dias após o plantio em todos os três locais.

O delineamento utilizado nos experimentos foi o de blocos casualizados, com parcelas de duas linhas de dez plantas. Os experimentos realizados em Pelotas e Londrina tiveram três repetições, enquanto, em Canoinhas, foram quatro repetições. O espaçamento foi de 0,75 m entre linhas e 0,40 $\mathrm{m}$ entre plantas. Não foi utilizada irrigação e as práticas agrícolas seguiram as recomendações para cada região.

Foram realizadas as seguintes avaliações:

- Ciclo vegetativo: avaliado nos experimentos de Pelotas e Canoinhas, aos 100 dias após o plantio, utilizando-se esca- 
las de notas (em Pelotas, nove pontos: 1- tardio, 9- precoce; em Canoinhas, cinco pontos: 1- tardio, 5- precoce).

- Massa total de tubérculos (kg.parcela-1 ${ }^{-1}$;

- Massa de tubérculos comerciais (tubérculos com diâmetro transversal > 45mm $\left(\mathrm{kg} \cdot\right.$ parcela $\left.^{-1}\right)$;

- Percentagem de massa de tubérculos comerciais [(massa de tubérculos comerciais/ massa total de tubérculos) $\mathrm{x}$ 100];

- Massa média de tubérculos comerciais (g);

- Número de tubérculos comerciais;

- Peso específico, medido com utilização de higrômetro;

- Cor de palitos fritos, avaliada, usando-se amostra de três tubérculos médios e sadios por parcela. Os tubérculos foram cortados, longitudinalmente, em forma de palitos com 9,5 mm, e fritos em gordura vegetal, à temperatura inicial de $180^{\circ} \mathrm{C}$, por $7 \mathrm{~min}$, no experimento de Pelotas, e por 2,5 min, nos experimentos de Canoinhas e Londrina. Em seguida, foram atribuídas notas de 1 a 9 (1- claro, 9escuro), no experimento de Pelotas, e notas de 1 a 5 (1claro a 5- escuro), nos experimentos de Canoinhas e Londrina.

Os dados obtidos foram verificados, quanto à distribuição normal dos erros, pelo teste de Lilliefors. Os dados de peso específico foram transformados por arcoseno da raiz quadrada de $\mathrm{X}$ e os dados de cor de palitos fritos, de Londrina, foram transformados por raiz quadrada de $\mathrm{x}+0,50$, para atender a esta pressuposição. Foram realizadas análises de variância individuais, por local, seguidas de agrupamentos de médias, obtidos pelo teste Scott $\& \operatorname{Knott}(\alpha=0,05)$. As análises foram realizadas com o programa GENES (Cruz, 2001).

\section{RESULTADOS E DISCUSSÃO}

As análises de variância mostraram que houve diferença significativa entre clones $(\mathrm{P}<0,05)$, para todos os caracteres avaliados (dados não apresentados).

Os coeficientes de variação (CV), que são indicativos da precisão experimental, foram maiores para o caráter massa de tubérculos comerciais (MTC) $(15,89 \%)$ e massa total de tubérculos (MTT) (14,20\%), em Pelotas, RS; para MTC (14,48\%) e ciclo vegetativo (CIC) $(15,88 \%)$ em Canoinhas, SC e, para coloração de palitos após a fritura (COR) (19,84 \%), em Londrina, PR (Tabelas 1 e 2). Quanto a MTT e MTC, que são componentes do rendimento de tubérculos, caráter quantitativo, portanto de grande influência ambiental, os valores de CV são semelhantes aos de outros estudos realizados com a cultura (Rodrigues \& Pereira, 2003; Silva et al., 2006; Costa et al., 2007; Bisognin et al., 2008). Da mesma forma, COR tem sido relatada na literatura como um caráter influenciado medianamente pelo ambiente (Rodrigues \& Pereira, 2003; Pereira et al., 2007).

Com relação às médias dos clones nos locais de avaliação, observou-se que o clone F80-03-06 apresentou a maior média para MTT, em Pelotas, formando um grupo isolado, diferindo significativamente dos demais clones. O segundo grupo foi formado por F68-04-06, F74-23-06, F53-01-06, F81-01-06, F52-03-06, F7426-06, F79-01-06 e F63-01-06, que também apresentaram médias significativamente superiores às de ambos os cultivares testemunhas. Em Canoinhas, os clones CL02-05 e F88-01-06 compuseram o grupo mais produtivo. Os clones F80-03-06, F74-23-06, F53-01-06, F81-01-06, F79-01-06, F63-01-06, F52-02-06, F4807-06, F27-03-06 e o cultivar testemunha Asterix formaram o segundo grupo de MTT, em Canoinhas, sendo significativamente superiores para o caráter, em relação ao cultivar Ágata. Em Londrina, o grupo que apresentou maior MTT foi constituído pelos clones F53-01-06, F8101-06, F80-03-06 e F27-03-06, enquanto os clones restantes e os cultivares testemunhas formaram o segundo grupo, com médias de MTT significativamente inferiores. Observando-se os genótipos que foram avaliados nos três locais, verifica-se que o clone F80-03-06 apresentou bom desempenho, principalmente em Pelotas e Londrina.

Em relação à massa de tubérculos comerciais (MTC), em Pelotas, o clone F80-03-06 constituiu individualmente o grupo superior, seguido pelos clones F68-04-06, F7423-06, F53-01-06, F81-01-06, F52-03-06, F74-26-06, F79-0106 e F63-01-06, que formaram o segundo grupo (Tabela 1). Em Canoinhas, o clone CL02-05 formou isoladamente o grupo de maior MTC, seguido do clone F48-07-06 como componente do segundo grupo e F88-01-06, F80-03-06, F74-23-06, F81-01-06, F79-01-06, F63-01-06, F52-02-06 e F27-03-06, no terceiro grupo. Em Londrina, o clone F5301-06 foi o mais destacado, seguido do grupo formado porF74-23-06, F81-01-06, F79-01-06 e F27-03-06.

Quanto à percentagem de massa de tubérculos comerciais (PMC), para Pelotas, a maioria dos clones foi incluída no agrupamento com as maiores médias: F8003-06, F68-04-06, F74-23-06, F53-01-06, F81-01-06, F52-03-06, F74-26-06, F79-01-06, F63-01-06 e F5202-06 (Tabela 1). Em Canoinhas, os clones CL02-05 e F48-07-06 apresentaram as maiores médias, enquanto a maioria dos clones foi alocada no segundo agrupamento: F80-03-06, F68-04-06, F74-23-06, F53-01-06, F8101-06, F74-26-06, F79-01-06, F63-01-06, F52-02-06, F85-01-06, F88-01-06 e F27-03-06. Já, em Londrina, os clones agrupados com os maiores valores de médias foram F74-23-06, F53-01-06, F81-01-06, F52-03-06, F74-26-06, F79-01-06, F63-01-06, Asterix, F85-01-06, 


\begin{tabular}{|c|c|c|c|c|c|c|c|c|c|c|c|c|}
\hline \multirow[t]{2}{*}{ Clone } & \multicolumn{3}{|c|}{$\begin{array}{l}\text { Massa total de tubérculos* } \\
\left.\text { (kg.parc. }{ }^{-1}\right)\end{array}$} & \multicolumn{3}{|c|}{$\begin{array}{l}\text { Massa de tubérculos comerciais } \\
\left.\text { (kg.parc. }{ }^{-1}\right)\end{array}$} & \multicolumn{3}{|c|}{$\begin{array}{l}\text { Percentagem da massa } \\
\text { de tubérculos comerciais }(\%)\end{array}$} & \multicolumn{3}{|c|}{$\begin{array}{l}\text { Massa média } \\
\text { de tubérculos comerciais (g) }\end{array}$} \\
\hline & Pel. & Can. & Lon. & Pel. & Can. & Lon. & Pel. & Can. & Lon. & Pel. & Can. & Lon. \\
\hline F80-03-06 & $25,56 \mathrm{a}$ & $23,98 \mathrm{~b}$ & $16,87 \mathrm{a}$ & $23,45 \mathrm{a}$ & $14,05 \mathrm{c}$ & $11,17 \mathrm{c}$ & $91,7 \mathrm{a}$ & $58,6 \mathrm{~b}$ & $66,2 b$ & $150,9 \mathrm{a}$ & $150,0 \mathrm{~b}$ & - \\
\hline F68-04-06 & $18,84 \mathrm{~b}$ & $19,23 \mathrm{c}$ & $13,43 \mathrm{~b}$ & $16,79 \mathrm{~b}$ & $11,40 \mathrm{~d}$ & $9,83 \mathrm{c}$ & $89,1 \mathrm{a}$ & $59,3 \mathrm{~b}$ & $73,2 \mathrm{~b}$ & $155,9 \mathrm{a}$ & $150,0 \mathrm{~b}$ & - \\
\hline F74-23-06 & $17,56 \mathrm{~b}$ & $24,01 \mathrm{~b}$ & $14,07 \mathrm{~b}$ & $16,58 \mathrm{~b}$ & $14,40 \mathrm{c}$ & $12,30 \mathrm{~b}$ & $94,4 \mathrm{a}$ & $60,0 \mathrm{~b}$ & $87,4 \mathrm{a}$ & $179,0 \mathrm{a}$ & $150,0 \mathrm{~b}$ & - \\
\hline F53-01-06 & $16,78 \mathrm{~b}$ & $22,55 \mathrm{~b}$ & $18,83 \mathrm{a}$ & $15,11 \mathrm{~b}$ & $13,10 \mathrm{~d}$ & 15,87 a & $90,0 \mathrm{a}$ & $58,1 \mathrm{~b}$ & $84,3 \mathrm{a}$ & $141,1 \mathrm{a}$ & $150,0 \mathrm{~b}$ & - \\
\hline F81-01-06 & $16,48 \mathrm{~b}$ & $25,85 \mathrm{~b}$ & $16,87 \mathrm{a}$ & $14,64 \mathrm{~b}$ & $16,45 \mathrm{c}$ & $13,73 \mathrm{~b}$ & $88,8 \mathrm{a}$ & $63,6 \mathrm{~b}$ & $81,4 \mathrm{a}$ & $150,8 \mathrm{a}$ & $160,0 \mathrm{~b}$ & - \\
\hline F52-03-06 & $16,40 \mathrm{~b}$ & - & $13,57 \mathrm{~b}$ & $14,53 \mathrm{~b}$ & - & $10,97 \mathrm{c}$ & $88,6 \mathrm{a}$ & - & $80,8 \mathrm{a}$ & $149,7 \mathrm{a}$ & - & - \\
\hline F74-26-06 & $15,69 \mathrm{~b}$ & $16,38 \mathrm{~d}$ & $12,17 \mathrm{~b}$ & $14,47 \mathrm{~b}$ & $9,05 \mathrm{e}$ & $10,60 \mathrm{c}$ & $92,2 \mathrm{a}$ & $55,3 \mathrm{~b}$ & $87,1 \mathrm{a}$ & $152,2 \mathrm{a}$ & $130,0 \mathrm{c}$ & - \\
\hline F79-01-06 & $15,50 \mathrm{~b}$ & $23,91 \mathrm{~b}$ & $14,53 \mathrm{~b}$ & $13,57 \mathrm{~b}$ & $13,85 \mathrm{c}$ & $12,10 \mathrm{~b}$ & $87,5 \mathrm{a}$ & $57,9 \mathrm{~b}$ & $83,3 \mathrm{a}$ & $139,5 \mathrm{a}$ & $160,0 \mathrm{~b}$ & - \\
\hline F63-01-06 & $15,38 \mathrm{~b}$ & $25,03 \mathrm{~b}$ & $13,50 \mathrm{~b}$ & $14,07 \mathrm{~b}$ & $16,30 \mathrm{c}$ & $11,47 \mathrm{c}$ & $91,5 \mathrm{a}$ & $65,1 \mathrm{~b}$ & $85,0 \mathrm{a}$ & $159,1 \mathrm{a}$ & $160,0 \mathrm{~b}$ & - \\
\hline Asterix & $12,87 \mathrm{c}$ & $24,35 \mathrm{~b}$ & $12,93 \mathrm{~b}$ & $9,13 \mathrm{c}$ & $9,35 \mathrm{e}$ & $10,10 \mathrm{c}$ & $70,9 \mathrm{~b}$ & $38,4 \mathrm{c}$ & $78,1 \mathrm{a}$ & $107,3 \mathrm{~b}$ & $150,0 \mathrm{~b}$ & - \\
\hline F52-02-06 & $12,38 \mathrm{c}$ & $24,48 \mathrm{~b}$ & - & $10,88 \mathrm{c}$ & $14,55 \mathrm{c}$ & - & $87,9 \mathrm{a}$ & $59,4 \mathrm{~b}$ & - & $143,4 \mathrm{a}$ & $140,0 \mathrm{c}$ & - \\
\hline F119-01-06 & $9,20 \mathrm{~d}$ & - & $13,70 \mathrm{~b}$ & $6,16 \mathrm{~d}$ & - & $11,07 \mathrm{c}$ & $67,0 \mathrm{~b}$ & - & $80,8 \mathrm{a}$ & $102,1 \mathrm{~b}$ & - & - \\
\hline Ágata & $9,12 \mathrm{~d}$ & $20,51 \mathrm{c}$ & $10,13 \mathrm{~b}$ & $7,58 \mathrm{c}$ & $8,90 \mathrm{e}$ & $7,73 \mathrm{c}$ & $83,1 \mathrm{~b}$ & $43,4 \mathrm{c}$ & $76,3 \mathrm{~b}$ & $120,5 \mathrm{~b}$ & $130,0 \mathrm{c}$ & - \\
\hline F85-01-06 & $7,08 \mathrm{~d}$ & $20,98 \mathrm{c}$ & $11,73 \mathrm{~b}$ & $3,23 \mathrm{~d}$ & $11,30 \mathrm{~d}$ & $9,23 \mathrm{c}$ & $45,6 \mathrm{c}$ & $53,9 \mathrm{~b}$ & $78,7 \mathrm{a}$ & $91,0 \mathrm{~b}$ & $130,0 \mathrm{c}$ & - \\
\hline CL02-05 & - & $30,06 \mathrm{a}$ & - & - & $22,15 \mathrm{a}$ & - & - & $73,7 \mathrm{a}$ & - & - & $170,0 \mathrm{~b}$ & - \\
\hline F88-01-06 & - & $28,46 \mathrm{a}$ & - & - & $17,00 \mathrm{c}$ & - & - & $59,7 \mathrm{~b}$ & - & - & $160,0 \mathrm{~b}$ & - \\
\hline F48-07-06 & - & $25,83 \mathrm{~b}$ & $13,87 \mathrm{~b}$ & - & $19,05 \mathrm{~b}$ & $11,50 \mathrm{c}$ & - & $73,8 \mathrm{a}$ & $82,9 \mathrm{a}$ & - & $220,0 \mathrm{a}$ & - \\
\hline F27-03-06 & - & $25,26 \mathrm{~b}$ & $16,33 \mathrm{a}$ & - & $16,40 \mathrm{c}$ & $13,17 \mathrm{~b}$ & - & $64,9 \mathrm{~b}$ & $80,6 \mathrm{a}$ & - & $150,0 \mathrm{~b}$ & - \\
\hline$\overline{\mathrm{CV}(\%)}$ & 14,20 & 9,64 & 13,73 & 15,89 & 14,48 & 13,92 & 7,15 & 8,85 & 6,50 & 9,99 & 9,21 & - \\
\hline
\end{tabular}

*Médias seguidas de mesma letra na coluna não diferem estatisticamente pelo teste de Scott-Knott a 5\% de probabilidade. 
F48-07-06, F27-03-06 e F119-01-06. Observando-se os genótipos que se agruparam entre os melhores para este caráter em pelo menos dois locais de cultivo, verifica-se que os clones F74-23-06, F53-01-06, F81-0106, F52-03-06, F74-26-06, F79-01-06, F63-01-06 e F48-07-06 apresentaram-se como os melhores. No entanto, para realizar a seleção baseada neste caráter, é necessário que os clones tenham também elevado rendimento e, neste sentido, pode-se verificar que, os clones F53-01-06 e F81-01-06 apresentaram desempenho intermediário, em Pelotas e Canoinhas, e foram agrupados entre os melhores, em Londrina. O clone F80-0306, que se destacou em relação à massa total de tubérculos não esteve entre aqueles com maior PMC. Correlação significativa, mas de reduzida magnitude, entre rendimento de tubérculos e percentagem de tubérculos comerciais, foi relatada por Costa et al. (2007).

Em relação à massa média de tubérculos comerciais (MMTC), em Pelotas, com exceção dos clones F119-01-06 e F85-01-06 e dos cultivares testemunhas Asterix e Ágata, todos os demais clones apresentaram elevada massa média de tubérculos comerciais (Tabela 1). Em Canoinhas, o clone F48-07-06 constituiu o primeiro grupo e os clones F80-03-06, F68-04-06, F74-23-06, F53-01-06, F81-01-06, F7901-06, F63-01-06, CL02-05, F88-01-05, F27-03-06 e o cultivar testemunha Asterix formaram o segundo grupo. Considerando-se os dados dos experimentos de Pelotas e Canoinhas, os clones F80-03-06, F68-04-06, F74-23-06, F5301-06, F81-01-06, F79-01-06, F63-01-06, F48-07-06 e F5203-06 apresentaram elevada MMTC, sendo que os dois últimos foram avaliados apenas em um local.

Considerando-se o número de tubérculos com tamanho comercial (Tabela 2), ou seja, aqueles que cresceram mais e atingiram pelo menos $45 \mathrm{~mm}$ de diâmetro, para Pelotas, destacaram-se o clone F80-03-06, seguido de vários outros genótipos que foram incluídos no segundo agrupamento de maior média: F68-04-06, F74-23-06, F5301-06, F81-01-06, F52-03-06, F74-26-06, F79-01-06, F63-0106 e Asterix. Em Canoinhas, o clone CL02-05 destacou-se dos demais, enquanto, no conjunto que formou o segundo melhor agrupamento, encontram-se os clones F80-0306, F74-23-06, F81-01-06, F63-01-06, F52-02-06, F88-01-06 e F27-03-06. Desta forma, verifica-se que os clones CL0205 e F80-03-06 sobressaíram-se em relação aos demais, em cada local de avaliação.

Os clones F80-03-06 e CL02-05, que apresentaram as maiores médias de massa de tubérculos comerciais, em Pelotas e Canoinhas, respectivamente, destacaram-se mais em relação ao número de tubérculos comerciais do que em relação à massa média de tubérculos comerciais; ou seja, este primeiro caráter foi mais importante na determinação do rendimento comercial desses clones. No caso de F80-03-06, em Pelotas, esse clone teve bom desempe- nho para os dois caracteres. Silva et al. (2012) verificaram uma forte relação entre o número de tubérculos comerciais e a massa média de tubérculos.

As médias dos caracteres peso específico e cor de palitos fritos estão apresentadas na Tabela 2. As médias de peso específico das testemunhas, obtidas neste estudo, foram semelhantes às obtidas por Pereira et al. (2008), com 1,062 e 1,070, e por Silva et al. (2012), com 1,062 e 1,082, para Ágata e Asterix, respectivamente. Em Pelotas, os clones F80-03-06, F68-04-06, F74-23-06, F53-01-06, F8101-06, F52-03-06, F74-26-06, F63-01-06, F52-02-06, F85-0106 e Asterix formaram o grupo superior de peso específico; em Canoinhas, os clones F80-03-06, F81-01-06, F8501-06 e F88-01-06, juntamente com a variedade Asterix, compuseram o grupo superior, seguidos dos clones F6804-06, F74-23-06, F53-01-06, F74-26-06, F79-01-06, F63-0106, F52-02-06, F48-07-06 e F27-03-06; em Londrina, os clones F80-03-06, F81-01-06, F85-01-06 e F48-07-06 formaram o grupo superior, seguidos dos clones F68-04-06, F7423-06, F53-01-06, F79-01-06 e Asterix. Observa-se que, nas três localidades, os clones F80-03-06, F81-01-06 e F85-0106 estiveram sempre incluídos nos grupos que apresentaram maior peso específico.

Quanto à fritura, o grupo de cor mais clara, em Pelotas, foi composto unicamente do clone F85-01-06, seguido do cultivar Asterix e do clone F81-01-06. Em Canoinhas, o grupo superior foi constituído pelos clones F48-07-06, F8801-05, F81-01-06 e Asterix e, o segundo grupo, pelos clones F85-01-06 e F53-01-06. Em Londrina, o grupo superior foi formado pelos clones F85-01-06, Asterix, F81-01-06, F4807-06, F68-04-06, F74-26-06 e F53-01-06. De maneira geral, observando-se os resultados de cada ambiente, verificase que os clones F81-01-06, F85-01-06, F48-07-06 e F8801-05 e o cultivar Asterix mostraram melhor desempenho para cor de palitos fritos.

$\mathrm{Na}$ classificação quanto ao ciclo vegetativo, o grupo de clones mais precoces, em Pelotas, foi composto por F119-01-06, F85-01-06 e a testemunha Ágata, enquanto, em Canoinhas, exceto os clones F88-01-06, F80-03-06, F8101-06 e F48-07-06, todos os demais estiveram no grupo mais precoce. Assim, observa-se que a testemunha Ágata e o clone F85-01-06 foram classificados como precoces em ambos os locais e os clones F119-01-06, CL02-05 e F27-03-06 também foram classificados como precoces, no entanto, foram avaliados em apenas um local. Os clones F68-04-06, F74-23-06, F52-03-06, F74-26-06, F79-01-06, F6301-06 e F88-01-05 e o cultivar Asterix foram classificados como de ciclo médio, e os clones F80-03-06, F53-01-06, F52-02-06, F119-01-06 e F48-07-06, como tardios. A classificação quanto ao ciclo vegetativo, verificada para as testemunhas, concorda com a de Silva et al. (2012), que também atestaram a precocidade do clone CL02-05. A busca por clones precoces e, ao mesmo tempo, produtivos, é um 
T Tabela 2. Médias para os caracteres número de tubérculos comerciais, peso específico, cor de palitos fritos e ciclo vegetativo de clones de batata, na safra de outono/11 em Pelotas-RS, safra de primavera/11 em Canoinhas-SC, e safra de outono/11 em Londrina-PR, Canoinhas-SC, Brasil

\begin{tabular}{|c|c|c|c|c|c|c|c|c|c|c|c|c|}
\hline \multirow{2}{*}{ Clone } & \multicolumn{3}{|c|}{ Número de tubérculos comerciais* } & \multicolumn{3}{|c|}{ Peso específico } & \multicolumn{3}{|c|}{ Cor de palitos fritos } & \multicolumn{3}{|c|}{ Ciclo vegetativo } \\
\hline & Pel. & Can. & Lon. & Pel. & Can. & Lon. & Pel. ${ }^{1 a}$ & Can. ${ }^{1 \mathrm{~b}}$ & Lon. & Pel. $^{2 a}$ & Can. $^{2 b}$ & Lon. \\
\hline F80-03-06 & & 155,67 a & $94,25 \mathrm{~b}$ & - & $1,072 \mathrm{a}$ & $1,088 \mathrm{a}$ & $1,084 \mathrm{a}$ & $8,23 \mathrm{a}$ & $3,75 \mathrm{a}$ & $3,00 \mathrm{a}$ & $4,00 \mathrm{c}$ & $2,75 \mathrm{c}$ \\
\hline F68-04-06 & & $107,67 \mathrm{~b}$ & $76,25 \mathrm{~d}$ & - & $1,074 \mathrm{a}$ & $1,083 \mathrm{~b}$ & $1,078 \mathrm{~b}$ & $7,63 \mathrm{a}$ & $3,00 \mathrm{~b}$ & $1,33 \mathrm{~b}$ & $5,67 \mathrm{~b}$ & $4,25 \mathrm{a}$ \\
\hline F74-23-06 & & $92,67 \mathrm{~b}$ & $93,50 \mathrm{~b}$ & - & $1,075 \mathrm{a}$ & $1,084 \mathrm{~b}$ & $1,078 \mathrm{~b}$ & $7,67 \mathrm{a}$ & $3,13 \mathrm{~b}$ & $2,33 \mathrm{a}$ & $5,67 \mathrm{~b}$ & $4,00 \mathrm{a}$ \\
\hline F53-01-06 & & $100,00 \mathrm{~b}$ & $85,75 \mathrm{c}$ & - & $1,075 \mathrm{a}$ & $1,082 \mathrm{~b}$ & $1,079 \mathrm{~b}$ & $7,80 \mathrm{a}$ & $2,75 \mathrm{c}$ & $1,67 \mathrm{~b}$ & $5,00 \mathrm{c}$ & $4,43 \mathrm{a}$ \\
\hline F81-01-06 & $97,67 \mathrm{~b}$ & $101,25 \mathrm{~b}$ & - & $1,078 \mathrm{a}$ & $1,094 \mathrm{a}$ & $1,086 \mathrm{a}$ & $4,40 \mathrm{~d}$ & $2,13 \mathrm{~d}$ & $1,33 \mathrm{~b}$ & $7,33 \mathrm{a}$ & $3,00 \mathrm{c}$ & - \\
\hline F52-03-06 & $103,00 \mathrm{~b}$ & - & - & $1,071 \mathrm{a}$ & - & $1,072 \mathrm{c}$ & $7,13 \mathrm{~b}$ & - & $2,33 \mathrm{a}$ & $6,00 \mathrm{~b}$ & - & - \\
\hline F74-26-06 & $94,33 \mathrm{~b}$ & $72,75 \mathrm{~d}$ & - & $1,074 \mathrm{a}$ & $1,082 \mathrm{~b}$ & $1,074 \mathrm{c}$ & $8,13 \mathrm{a}$ & $3,00 \mathrm{~b}$ & $1,33 \mathrm{~b}$ & $5,33 \mathrm{~b}$ & $4,43 \mathrm{a}$ & - \\
\hline F79-01-06 & $97,67 \mathrm{~b}$ & $89,25 \mathrm{c}$ & - & $1,061 \mathrm{~b}$ & $1,084 \mathrm{~b}$ & $1,077 \mathrm{~b}$ & $7,67 \mathrm{a}$ & $3,25 \mathrm{~b}$ & $2,33 \mathrm{a}$ & $6,33 \mathrm{~b}$ & $4,78 \mathrm{a}$ & - \\
\hline F63-01-06 & $88,33 \mathrm{~b}$ & $104,00 \mathrm{~b}$ & - & $1,076 \mathrm{a}$ & $1,083 \mathrm{~b}$ & $1,076 \mathrm{c}$ & $7,97 \mathrm{a}$ & $3,38 \mathrm{~b}$ & $2,33 \mathrm{a}$ & $6,33 \mathrm{~b}$ & $4,35 \mathrm{a}$ & - \\
\hline Asterix & $85,00 \mathrm{~b}$ & $60,50 \mathrm{~d}$ & - & $1,081 \mathrm{a}$ & $1,091 \mathrm{a}$ & $1,081 \mathrm{~b}$ & $3,13 \mathrm{e}$ & $2,13 \mathrm{~d}$ & $1,00 \mathrm{~b}$ & $5,67 \mathrm{~b}$ & $4,50 \mathrm{a}$ & - \\
\hline F52-02-06 & $76,00 \mathrm{c}$ & $100,75 \mathrm{~b}$ & - & $1,070 \mathrm{a}$ & $1,083 \mathrm{~b}$ & - & $6,53 \mathrm{c}$ & $3,00 \mathrm{~b}$ & - & $5,00 \mathrm{c}$ & $4,50 \mathrm{a}$ & - \\
\hline F119-01-06 & $60,67 \mathrm{c}$ & - & - & $1,061 \mathrm{~b}$ & - & $1,065 \mathrm{~d}$ & $6,47 \mathrm{c}$ & - & $2,67 \mathrm{a}$ & $8,00 \mathrm{a}$ & - & - \\
\hline Ágata & $64,33 \mathrm{c}$ & $67,75 \mathrm{~d}$ & - & $1,066 \mathrm{~b}$ & $1,066 \mathrm{~d}$ & $1,063 \mathrm{~d}$ & $6,13 \mathrm{c}$ & $3,50 \mathrm{a}$ & $3,00 \mathrm{a}$ & $8,00 \mathrm{a}$ & $5,00 \mathrm{a}$ & - \\
\hline F85-01-06 & $35,67 \mathrm{~d}$ & $81,50 \mathrm{c}$ & - & $1,081 \mathrm{a}$ & $1,092 \mathrm{a}$ & $1,086 \mathrm{a}$ & $1,87 \mathrm{f}$ & $2,50 \mathrm{c}$ & $1,00 \mathrm{~b}$ & $8,33 \mathrm{a}$ & $4,43 \mathrm{a}$ & - \\
\hline CL02-05 & - & $127,50 \mathrm{a}$ & - & - & $1,071 \mathrm{c}$ & - & - & $3,88 \mathrm{a}$ & - & - & $4,25 \mathrm{a}$ & - \\
\hline F88-01-06 & - & $106,25 \mathrm{~b}$ & - & - & $1,087 \mathrm{a}$ & - & - & $2,13 \mathrm{~d}$ & - & - & $3,50 \mathrm{~b}$ & - \\
\hline F48-07-06 & - & $86,75 \mathrm{c}$ & - & - & $1,085 \mathrm{~b}$ & $1,088 \mathrm{a}$ & - & $2,00 \mathrm{~d}$ & $1,33 \mathrm{~b}$ & - & $2,70 \mathrm{c}$ & - \\
\hline F27-03-06 & - & $110,00 \mathrm{~b}$ & - & - & $1,083 \mathrm{~b}$ & $1,075 \mathrm{c}$ & - & $3,25 \mathrm{~b}$ & $3,33 \mathrm{a}$ & - & $4,35 \mathrm{a}$ & - \\
\hline $\mathrm{CV}(\%)$ & 11,87 & 10,98 & - & 3,32 & 0,19 & 1,55 & 4,86 & 7,81 & 19,84 & & 10,09 & 15,88 \\
\hline
\end{tabular}

${ }^{1 \mathrm{a} C}$ Cor de palitos fritos: 1- clara, 5- escura; ${ }^{\mathrm{lb}} \mathrm{Cor}$ de palitos fritos: 1- clara, 9- escura; ${ }^{2 \mathrm{C} C i c l o}$ vegetativo: 1 - tardio, 9- precoce; ${ }^{2 \mathrm{~b} C i c l o}$ vegetativo: 1 - tardio, 5- precoce.

*Médias seguidas de mesma letra na coluna não diferem estatisticamente pelo teste de Scott-Knott a $5 \%$ de probabilidade. 
grande desafio, pois, de modo geral, genótipos tardios tendem a ser mais produtivos do que os precoces (Rodrigues et al., 2009; Silva \& Pinto, 2005).

De maneira geral, verifica-se que os genótipos foram agrupados diferentemente, em cada local, principalmente em relação a caracteres de massa de tubérculos, número de tubérculos e ciclo vegetativo, indicando a necessidade de avaliações em vários ambientes, para a identificação de materiais superiores. Situação diferente foi verificada para os caracteres relacionados com o processamento, em que muita similaridade foi verificada entre os ambientes. Isso pode ser atribuído à maior herdabilidade dos caracteres de processamento do que àqueles relacionados com o rendimento de tubérculos, muito embora este parâmetro dependa da diversidade genética do material em estudo e das condições ambientais (Simon et al, 2009; Bheringi et al, 2009).

Examinando-se os resultados deste trabalho, na perspectiva da identificação de clones mais apropriados para o mercado 'in natura', em que, para os produtores, é fundamental o elevado potencial produtivo e a precocidade, comparando-se com o cultivar testemunha Ágata, verifica-se superioridade em ambos os locais do clone F80-0306 , que se destacou pela produtividade, apesar de ciclo vegetativo um pouco tardio. O clone CL02-05 destacouse que em relação à produtividade e também ao ciclo vegetativo, em Canoinhas.

Para industrialização, em que o peso específico, cor de fritura, rendimento de tubérculo e ciclo vegetativo não muito tardio são caracteres muito importantes, comparando-se com o cultivar testemunha Asterix, o clone F81-01-06, apesar de não apresentar os maiores rendimentos totais, apresenta tubérculos grandes, ciclo vegetativo não muito longo e boa aptidão para fritura. A seleção de clones com maior peso específico e, ao mesmo tempo, não muito tardios, é dificultada pela existência de uma relação positiva entre o ciclo vegetativo e o conteúdo de massa seca nos tubérculos (Silva \& Pinto, 2005; Silva et al., 2012).

\section{CONCLUSÕES}

Para o mercado 'in natura', comparando-se com o cultivar testemunha Ágata, os clones que se apresentaram como mais promissores foram F80-03-06 e CL02-05.

Para processamento industrial, comparando-se com o cultivar testemunha Asterix, o clone F81-01-06 destacou-se em relação aos demais.

\section{AGRADECIMENTOS}

Os autores agradecem ao CNPq, pelo auxílio financeiro ao Programa de Melhoramento Genético de Batata da Embrapa.

\section{REFERÊNCIAS}

Bheringi LL, Pinto CABP, Benites FRG, Leite ME \& Silva FL (2009) Seleção assistida por marcadores para teor de matéria seca e açúcares redutores em tubérculos de batata. Ciência Rural, 39:38-44.

Bisognin DA, Müller DR, Streck NA, Andriolo JL \& Sausen D (2008) Desenvolvimento e rendimento de clones de batata na primavera e no outono. Pesquisa Agropecuária Brasileira, 43:699-705.

Costa LC, Bisognin DA, Andriolo JL, Ritter CEL \& Bandinelli MG (2007) Identificação de clones de batata com potencial para mesa e adaptados para os cultivos de outono e primavera do Rio Grande do Sul. Ciência e Natura, 29:93-104.

Cruz CD (2001) Programa genes: aplicativo computacional em genética e estatística. Viçosa, UFV. 648p.

Dias GS, Silva EC \& Maciel GM (2003) Competição de cultivares de batata na Região de Alfenas-MG. In: $43^{\circ}$ Congresso Brasileiro de Olericultura, Recife. SOB, CD-ROM.

Empresa Brasileira de Pesquisa Agropecuária - Embrapa (2006) Sistema brasileiro de classificação de solos. Rio de Janeiro, Centro Nacional de Pesquisa de Solos. 306p.

Freitas ST, Bisognin DA, Gómeza CS, Sautter CK, Costa LC \& Rampelotto MV (2006) Qualidade para processamento de clones de batata cultivados durante a primavera e outono no Rio Grande do Sul. Ciência Rural, 36:80-85.

Gadum J, Pinto CABP \& Rios MCD (2003) Desempenho agronômico e reação de clones de batata (Solanum tuberosum L.) ao PVY. Ciência eAgrotecnologia, 27:1484-1492.

Pereira A da S, Fritsche Neto R, Silva RS, Bender CI, Schünemann AP, Ferri NML \& Vendruscolo JL (2007) Genótipos de batata com baixo teor de açúcares redutores. Horticultura Brasileira, 25:220-223.

Pereira A da S, Ney VG, Terres LR, Treptow RO \& Castro LAS de (2008) Caracteres de produção e qualidade de clones de batata selecionados de população segregante para resistência ao vírus $\mathrm{Y}$ da batata. Pelotas, Embrapa Clima Temperado. 18p. (Boletim de Pesquisa e Desenvolvimento, 67).

Rodrigues AFS \& Pereira A da S (2003) Correlações inter e intragerações e herdabilidade de cor de chips, matéria seca e produção em batata. Pesquisa Agropecuária Brasileira, 38:599-604.

Rodrigues GB (2006) Seleção divergente para duração do ciclo vegetativo em batata. Dissertação de Mestrado. Universidade Federal de Lavras, Lavras. 55p.

Rodrigues GB, Pinto CAB, Benites FRG \& Melo DS (2009) Seleção para duração do ciclo vegetativo em batata e relação com a produtividade de tubérculos. Horticultura Brasileira, 27:280-285.

Silva LAS \& Pinto CABP (2005) Duration of the growth cycle and the yield potential of potato genotypes. Crop Breeding and Applied Biotechnology, 5:20-28.

Silva GO da, Souza VQ de, Pereira A da S, Carvalho FIF de \& FritscheNeto R (2006) Early generation selection for tuber appearance affects potato yield components. Crop Breeding and Applied Biotechnology, 6:73-78.

Silva GO, Castro CM, Terres LR, Rohr A, Suinaga FA \& Pereira AS (2012) Desempenho agronômico de clones elite de batata. Horticultura Brasileira, 30:557-560.

Simon GA, Pinto CABP, Lambert E de S \& Andreu MA (2009) Seleção de clones de batata resistentes à pinta preta e tolerantes ao calor. Ceres, 56:31-37.

Souza ZS, Bisognin DA, Junior GRM \& Gnocato FS (2011) Seleção de clones de batata para processamento industrial em condições de clima subtropical e temperado. Pesquisa Agropecuária Brasileira, 46:1503-1512. 